TE DEUM: Jurnal Teologi dan Pengembangan Pelayanan

Volume 10, Nomor 1 (Desember 2020): 107-119

ISSN 2252-3871 (print), 2746-7619 (online)

http://ojs.sttsappi.ac.id/index.php/tedeum/index

\begin{tabular}{|l|l|l|}
\hline Submitted: $12-6-2020$ & Accepted: 11-11-2020 & Published: 28-12-2020 \\
\hline
\end{tabular}

\title{
PEMBELAJARAN PENDIDIKAN AGAMA KRISTEN DALAM KELUARGA DI ERA DIGITAL
}

\author{
Fredik Melkias Boiliu \\ Universitas Kristen Indonesia, Jakarta \\ boiliufredik@gmail.com
}

\begin{abstract}
This article discusses how parents discuss Christian religious education in families in the digital age to improve children's spirituality and morality. In this era, all buman activities are carried out online both work activities, education and worship. The activities carried out online have a positive and negative impact. In this discussion, the author will discuss the negative of online activities on the spiritual and moral of children. Therefore, parents have a very important role in the family to shape the spiritual and moral of the child because the good or bad spiritual and moral child depends on the role of parents in the family. With the help of parents, children will have a good and strong spiritual and moral improvement in the instant and sophisticated era of today. The method used in this update is literature review and library research.
\end{abstract}

Keywords: Digital Era, Family, Morality, Spirituality, Christian Religious Education.

\section{ABSTRAK}

Artikel ini mengulas tentang pembelajaran pendidikan agama Kristen dalam keluarga di era digital untuk meningkatan spiritualitas dan moralitas anak. Orangtua merupakan sosok utama yang mewariskan nilai-nilai spiritualitas dan moralitas pada anak sejak dini melalui pengajaran pendidikan agama Kristen. Spiritualitas dan moralitas merupakan hal yang sangat mendasar dalam kehidupan anak. Di samping itu, era digital membawa dampak positif dan negatif bagi kehidupan anak. Dalam hal ini, dampak negatifnya sangat memengaruhi pertumbuhan spiritualitas dan moralitas anak. Oleh sebab itu, orangtua harus bertanggung untuk meningkat spiritualitas dan 
moralitas anak melalui pengajaran pendidikan agama Kristen dalam keluarga. Orangtua harus mengajarkan nilai-nilai spiritualitas dan moralitas pada anak berulang-ulang dimana saja dan kapanpun. Metode yang digunakan dalam penulisan ini adalah kajian literatur dan riset pustaka.

Kata kunci: era digital, keluarga, moralitas, spiritualitas, pendidikan agama Kristen.

\section{PENDAHULUAN}

Hasil survei tahun 2015 yang dilakukan oleh Lembaga PBB untuk anak UNICEF bersama para mitra yang salah satunya adalah dari Kementerian Komunikasi dan Informatika dan Universitas Harvard Amerika Serikat, menyatakan bahwa dari 400 responden berusia 10-19 tahun dari seluruh Indonesia dan mewakili daerah pedesaan dan perkotaan, dapat ditemukan bahwa sebanyak 98 persen dari anak dan remaja mengaku tahu tentang internet dan 79,5 persen di antaranya adalah pengguna internet (Rahmatullah 2017). Disampaikan juga bahwa para penggunanya yakni kaum remaja dan anak sangat rentan melakukan penyimpangan perilaku yang diakibatkan oleh internet tersebut, apalagi bila tidak ada pendampingan dari orang tua. Data lain yang berhasil ditemukan adalah data dari Komisi Perlindungan Anak Indonesia yang menyatakan bahwa sejak tahun 2014 hingga tahun 2015 jumlah anak korban pornografi yang dilakukan mencapai jumlah 1.022 anak, dengan rinciannya adalah anak-anak yang menjadi korban pornografi online sebesar 28\%, pornografi anak online $21 \%$, prostitusi anak online $20 \%$, objek cd porno $15 \%$ serta anak korban kekerasan seksual online 11\% (Fatmawati 2019).

Berdasarkan data statistik yang dilakukan oleh Asosiasi Penyelenggara Jasa Internet Indonesia (APJII) tahun 2016, menyebutkan bahwa jumlah total pengguna internet di Indonesia sekitar 132,7 juta pengguna. Angka tersebut mengalami pertumbuhan sebesar 51,8 persen dibandingkan dengan survei yang dilakukan pada tahun 2014 (Indonesia. 2020). Tahun 2017 total pengguna internet naik menjadi 143,26 juta jiwa dan berdasarkan komposisi usia pengguna internet, pengguna internet anak-anak sekitar 16,68\% atau sekitar 23,89 juta jiwa (Maulidiyah 2018). Hal yang cukup mengejutkan bahwa di usia muda telah banyak anak yang menggunakan internet. Arus internet yang semakin luas dan dapat dinikmati oleh semua pihak tentunya memberikan kemudahan yang luar biasa dan tidak dapat disangkal. Namun, kemudahan tersebut haruslah diwaspadai, karena kemudahan yang dimaksud tidak hanya dari segi positif 
tapi juga dalam arti negatif. Berdasarkan fakta saat ini, anak-anak sudah akrab dengan perubahan di era digital, terutama dengan penggunaan internet. Penelitian yang dilakukan di Surabaya pada anak usia 6-12 tahun menyebutkan bahwa responden yang paling banyak menggunakan internet pertama usia 8 tahun (27\%), dan yang menarik adalah beberapa respondennya telah mengenal internet sejak balita yakni sejak 5 tahun $(12 \%), 4$ tahun (4\%) dan 3 tahun (1\%) (Candra 2013). Hal ini tentunya harus diperhatikan oleh orangtua, karena selain mencari informasi, anakanak usia 10-14 tahun sering menonton video, salah satunya di situs You Tube yang menghasilkan prestasi luar biasa, yakni selama 12 tahun tidak kurang 300 juta video diunggah setiap menitnya dengan jumlah penonton mencapai 2 milliar perbulan. Selain itu, media sosial merupakan jenis konten internet yang paling sering diakses yakni mencapai 97,4\% atau 129,2 juta pengguna (Sukmanjaya 2017).

Sesuai dengan hasil survei tersebut di atas maka dapat disimpulkan bahwa dampak negatif dari era digital sangat memengaruhi spiritualitas dan moralitas anak. Oleh sebab itu, orangtua harus bertanggung untuk meningkatkan spiritualitas dan moralitas anak melalui pengajaran pendidikan agama Kristen dalam keluarga. Pendidikan agama Kristen pada dasarnya merupakan pendidikan yang bercorakkan moral-moral Kristiani. Dalam hal ini, materi pengajaran pendidikan agama Kristen merupakan materi yang berisi tentang nilai-nilai kebenaran iman Kristen (Rifai 2012). Pendidikan agama Kristen juga berusaha untuk menumbuhkan dan membimbing sikap hidup yang sesuai nilai-nilai Kristiani supaya terbentuk pribadi Kristen yang sejati (Homrighausen 2012:19). Pendidikan agama Kristen berfungsi sebagai penyampaian kebenaran yang dinyatakan Tuhan dalam Alkitab. Artinya bahwa tidak dapat dipungkiri bahwa, tanggung jawab pendidikan agama Kristen pertama-tama dan terutama terletak pada orang tua, yaitu ayah dan ibu (Amsal 1:8) (Nainggolan 2009:28).

Spiritualitas merupakan potensi yang harus dimiliki oleh anak sejak dini, karena pengaruhnya sangatlah besar dalam kehidupan anak kelak dimasa depan. Dalam hal ini, anak memiliki spiritualitas sejak dini sangat penting karena akan menentukan bagi perkembangan anak ketika dewasa kelak. Jika sejak awal diberi dengan stimulasi spiritual yang baik, maka ke depannya dapat menerapkan nilai-nilai spiritualitas tersebut dalam kehidupan sehari-hari (Nuryanto 2017). Spiritualitas merupakan potensi yang harus dimiliki oleh anak sejak dini, karena pengaruhnya sangatlah besar dalam kehidupan anak kelak dimasa depan. Dalam hal ini, anak memiliki spiritualitas sejak dini sangat penting karena akan menentukan 
bagi perkembangan anak ketika dewasa kelak. Jika sejak awal diberi dengan stimulasi spiritual yang baik, maka ke depannya dapat menerapkan nilainilai spiritualitas tersebut dalam kehidupan sehari-hari (Nuryanto 2017).

Peningkatan spiritualitas pada anak di era digital sangatlah penting untuk mengembangkan potensi dirinya agar menjadi manusia yang percaya kepada Tuhan Yesus dengan sungguh-sungguh. Spiritualitas Kristen yang sejati adalah keberadaan seseorang yang berada di dalam relasi yang benar dengan Allah, sesama, dan ciptaan yang lain. artinya benar itu bukan berbicara tentang what is (apa yang terjadi), melainkan what ought to (apa yang seharusnya terjadi). Dalam hal ini, apa yang seharusnya terjadi maka tentu saja kehidupan anak harus mengacu pada apa yang dinyatakan oleh firman Tuhan. Spiritualitas Kristen yang sejati menurut firman Tuhan adalah keberadaan seseorang yang tahu bagaimana ia seharusnya berelasi dengan Tuhan, sesama, dirinya sendiri dan ciptaan lain dan hidup berdasarkan apa yang ia tahu tersebut (Tanudjaja 2018:29-30).

Peningkatan moral anak di era digital sangatlah penting sebab moralitas merupakan sesuatu tentang baik dan buruk yang terdapat dimanamana dan pada segala zaman (Bertens 2011:14). Norma-norma moral adalah tolok ukur yang dipakai masyarakat untuk mengukur kebaikan seseorang. Sehingga moralitas sebagai sikap hati orang yang terungkap dalam tindakan lahiriah. Moralitas terjadi apabila orang mengambil sikap yang baik karena ia sadar akan kewajiban dan tanggung jawabnya dan bukan karena ia mencari keuntungan. Moralitas juga merupakan sikap dan perbuatan baik yang betul-betul tanpa pamrih dan hanya moritaslah yang bernilai secara moral (Budiningsih 2004:24).

Dengan demikian, peningkatan spiritualitas dan moralitas anak di era digital merupakan hal penting yang perlu ditingkatkan melalui pengajaran pendidikan agama Kristen yang dilakukan oleh orangtua dalam lingkungan keluarga sehingga anak tetap mengikuti perkembangan zaman dan kecanggihan teknologi tanpa meninggalkan nilai-nilai spiritualitas dan moralitas dalam dirinya.

\section{METODE PENELITIAN}

Metode penelitian yang digunakan dalam penelitian ini adalah studi kepustakaan. Ini berarti bahwa penelitian ini mengacu pada data atau bahan tertulis yang berkaitan dengan topik diskusi yang diangkat, tentu saja penelitian ini menggunakan ide-ide tertulis sebagai sumber penekanan pada interpretasi dan analisis makna konsep pemikiran dalam bentuk ekspresi 
baik ide empiris dan ide-ide rasional. Sumber data dalam penelitian ini memiliki hubungan langsung dengan gagasan pendidikan agama Kristen, spiritualitas dan moralitas anak. Selain itu, penulis merujuk pada buku-buku oleh orang lain yang membahas wacana pendidikan berbasis keterbukaan untuk memfasilitasi pemahaman (Hadi 2011).

\section{HASIL DAN PEMBAHASAN}

\section{KEMEROSOTAN SPIRITUALITAS DAN MORALITAS ANAK DI ERA DIGITAL}

Era digital memberikan dampak terhadap spiritualitas generasi muda saat ini. teknologi dan kehidupan pribadi dan sosial seakan telah melebur dan menjadi kebutuhan hampir setiap orang, termasuk anak. Perkembangan teknologi membentuk pola dan relasi yang baru antar manusia dan dirinya sendiri, sesama, alam bahkan dengan Allah.

Kehadiran era digital membawa dampak positif dan juga negatuf. Dampak negatif dari era digital terjadi kemerosotan nilai-nilai moralitas dan spiritualitas pada anak. Merosotnya nilai moral pada anak memang menjadi keprihatinan serius pemerintah dan masyarakat, namun di era serba digital sekarang dengan arus teknologi infomasi yang sulit dibendung menjadikan persoalan tersebut tidak sederhana. Media yang tanpa kontrol dapat dengan mudah mencuci otak anak melalui game online. Anak lebih tertarik pada handphone (android-nya) dari pada permainan tradisional, dongeng, dan lagu-lagu anak yang sarat dengan pendidikan. Bahkan iklan barang haram seperti miras dan nakotika dikemas secara menarik bagi anak melalui internet dalam bentuk game online menambah kompleksitas persoalan moralitas anak dan spiritualitas (Setiawan 2017).

Generasi saat ini adalah generasi yang mengalami krisis secara global. Walaupun pada realitanya tidak semua mengalami krisis, tetapi searah perkembangan zaman generasi ini sudah dipengaruhi oleh beberapa faktor yang dapat mengubah seluruh aspek kehidupan baik spiritual maupun moral (Boiliu 2016). Dalam hal ini, generasi ini dipengaruhi beberapa faktor yang jika dibiarkan dan tidak ada pembimbingan secara serius dan terus menerus maka akan memunculkan generasi pemberontak. Dengan demikian, ada beberapa faktor itu antara lain: "media massa yang memberikan sajian gambar amoral, penyalahgunaan obat-obatan terlarang secara berlebihan, konsep intelektualitas menggantikan moralitas, gerakan zaman baru yang memberikan harapan-harapan palsu (Tong 2001:12). 


\section{Pembelajaran Pendidikan Agama Kristen Dalam KELUARGA DI ERA DIGITAL}

Rumah adalah latar yang paling ideal untuk menghubungan kebenaran dan hidup dengan anak-anak. Para orangtua Kristen mempunyai kepedulian agar anak-anak mereka bertumbuh secara rohani dan jasmani. Para orangtua diperintahkan untuk mengajarkan Alkitab kepada anak-anak (Lebar 2006:34-35). Dasar pendidikan Allah adalah pendidikan keluarga dan pusat pendidikan agama dalam Ulangan 6:4-9 adalah keluarga. Dalam hal ini, sang ayah mengajar bahwa pendidikan agama Kristen berpusat pada hukum Allah dank urban melalui sistem imamat sebagai berikut: (a) Allah telah memberikan Sepuluh Hukum kepada umat Israel (Kel.20:1-17), (b) perintah untuk mengasihi Allah (Ul.6:4-9), (c) adanya peraturan-peraturan yang mengatur ibadah dan hubungan sosial (GP 2017:5-26). Allah mendirikan keluarga agar anak belajar dari orangtua. Sebelum membentuk jemaat dan pemerintah, Allah menabiskan pernikahan dan keluarga sebagai bangunan dasar masyarakat. Tidak ada tempat yang lebih baik dan penting untuk menumbuhkan iman, dan menaburkan nilai-nilai kristiani selain keluarga (Harianto GP 2012:69).

Keluargalah yang merupakan pelaku dan sekaligus lingkungan primer bagi pembentukan watak, tata nilai dan disiplin anak sebelum memasuki usia sekolah, dan dunia masyarakat (Sidjabat 1994:63). Keluarga merupakan lembaga yang fenomenal dan universal, di mana di dalamnya terdapat anak-anak yang dipersiapkan untuk bertumbuh (Kristianto 2006:137). Keluarga sebagai pendidik utama di mana keluarga meletakkan dasar spiritual iman Kristen dan moral (Lase 2011:61). Keluarga adalah sebuah institusi pendidikan yang utama dan bersifat kodrati (Djamarah 2013:3). Dengan melihat hal tersebut, keluarga memiliki arti yang sangat penting dan utama dalam mengajarkan anak yang dianugerahkan Tuhan kepada setiap orang tua, sehingga anak tersebut bertumbuh di dalam pengenalan akan kebenaran firman Tuhan dan memiliki kepribadian yang sesuai dengan kebenaran Firman Tuhan yang menjadi dasar dan pedoman dalam setiap langkah kehidupan anak tersebut.

Didalam keluargalah anak-anak mendapatkan pengajaran iman dan nilai-nilai moral (Hastuti 2013). Dengan bersandar kepada anugerah Tuhan, orangtua mendidik anak-anaknya sejak kecil dengan pola Alkitabiah sehingga mereka memiliki karakter Kristus (Santoso 2014). Dengan demikian, pembelajaran pendidikan agama Kristen dimulai dari keluarga. Anak harus dididik dan didorong untuk menerapkan semua nilai-nilai 
sebagaimana diajarkan firman Tuhan, dan dijauhkan dari segala hal yang dilarang firman Tuhan (Gulo 2017). Oleh sebab itu, orangtua dalam keluarga harus mengajarkan anak untuk menanamkan nilai-nilai kristiani dalam kehidupan sehari-hari. Meskipun orangtua sebagai pengajar pertama dan utama dalam pertumbuhan kerohanian anak, tetapi orangtua harus menyadari bahwa Tuhanlah yang mengubah hati anak, orangtua hanya alat yang dipakai Tuhan dalam proses itu (Turansky 2014:163). Artinya bahwa sebagaimana yang dijelaskan dalam I Korintus 3:6 bahwa, Paulus menanam, Apolos menyiram, tetapi Allah yang memberi pertumbuhan. Kerohanian adalah sikap hidup yang mengamalkan daya Roh kudus dalam diri anak, supaya anak berkembang menjadi citra Allah yang semakin sesuai dengan cita-cita Sang Pencipta, di mana di dalamnya Roh Kudus mendorong setiap orang beriman dan memampukannya untuk mencapai tahap kedewasaannya dalam Kristus (Pribadi 2010:26).

\section{PEMBELAJARAN PAK DALAM PENINGKATAN SPIRITUALITAS ANAK DI ERA DIGITAL}

Pembelajaran pendidikan agama Kristen di era digital sangat penting untuk meningkatkan spiritualitas anak. Dalam hal ini, spiritualitas anak yang terpengaruh karena kehadiran era digital atau yang nantinya terpengaruh harus ditingkatkan melalui pembelajaran pendidikan agama Kristen dalam keluarga. Peningkatan spiritualitas anak di era digital melalui pembelajaran pendidikan agama Kristen dalam keluarga dilakukan oleh orangtua. Oleh sebab itu, orangtua sebagai pengajar yang mengajarkan nilai-nilai spiritualitas pada anak dalam keluarga harus terus mengajarkan berulangulang. Dalam hal ini, melalui pembelajaran pendidikan agama Kristen dalam keluarga, maka orangtua mengajarkan anak agar memiliki karakteristik spritualitas Kristen yang berdasarkan norma-norma dan perintah yang Alkitabiah, sehingga secara individual bisa mengatasi dirinya untuk menjauh dari dosa dan kenakalan-kenakalan sosial, ketidakadilan, gerakan ektrimisme, radikal bisa diatasi (Rumahorbo 2019).

Peningkatan/perkembangan spiritualitas dipahami sebagai suatu kebutuhan terhadap agama dan manusia sebagai makluk religius dianugerahi kemampuan dan perasaan untuk mengenal dan melakukan ajaranNya atau dapat juga dikatakan bahwa manusia diberikan karunia naluri beragama atau insting religius, dan ini merupakan kemampuan dasar yang berpeluang untuk berkembang dengan syarat lingkungan dalam hal ini orangtua dapat bertanggung jawab untuk meningkatkan spiritualitas anak 
melalui pengajaran pendidikan agama Kristen dalam keluarga. Dalam hal ini, pengajaran pendidikan agama Kristen dalam keluarga memiliki pengaruh yang sangat besar dalam peningkatan spiritualitas anak (Carolina L. Radjah 2020).

Dengan demikian, untuk meningkatkan spiritualitas anak melalui pembalajaran pendidikan agama krisetan dalam keluarga yakni: (a) orangtua sebagai pembentuk pribadi yang pertama bagi anak, dan tokoh yang ditiru maka orangtua seharusnya menjadi pribadi yang baik, pantas diidentifikasi anak, orangtua harus menjadi role model bagi anak, (b) orangtua hendaknya memperlakukan anaknya dengan baik, tidak mempertontonkan sikap otoriter, respek dan menghargai pribadi anak, mau mendengar pendapat dan keluhan anak, memaafkan dan meminta maaf bila orangtua melakukan kesalahan, meluruskan kesalahan anak dengan cara yang tepat, (c) orangtua hendaknya memelihara hubungan yang harmonis antar anggota keluarga sebab hubungan harmonis dan penuh pengertian akan berpengaruh secara signifikan terhadap perkembangan perilaku yang baik pula, (d) orangtua hendaknya mengajarkan dan melatih anak agar senantiasa bersyukur atas berkat yang telah diberikan, bersikap jujur dan tidak melakukan hal-hal yang menyakitkan orang lain (Carolina L. Radjah 2020).

Peningkatan spiritualitas anak di era digital melalui pembelajaran pendidikan agama Kristen dalam keluarga, orangtua harus mengajarkan anak untuk mengasihi Tuhan. Orangtua mengajarkan anak untuk mengasihi Tuhan secara berulang-ulang akan dapat meningkatkan spritualitas anak. Peningkatan spiritualitas anak bukan sekadar pilihan yang boleh dipilih, dan boleh juga tidak namun pembentukan spiritualitas anak adalah suatu kenyataan hidup yang utama (Thompson 2011:10-11). Orangtua mutlak bertanggung jawab dalam mengajarkan spiritualitas pada anak-anaknya karena meningkatan spiritualitas anak-anak oleh orangtua tidak boleh diabaikan melainkan orangtua harus menganggapnya sebagai yang paling utama. Dalam hal ini, untuk meningkat spiritualitas anak di era digital, orangtua harus mengajarkan anak untuk mengasihi Tuhan dalam kehidupannya secara berulang-ulang sebagaimana dalam kitab Ulangan 6:49. Allah menyatakan bahwa Ia menghendaki umat-Nya dengan sungguh mengajarkan kepada anak-anak mereka untuk mengasihi Dia dengan segenap hati, segenap jiwa, dan segenap kekuatan. Artinya, sejak kecil, anak-anak sudah harus diajarkan untuk mengasihi Tuhan Allah dengan sungguh-sungguh, melebihi apapun dan siapapun di dalam dunia ini, semakin hari semakin kuat serta menjadikan Dia sebagai pusat hidup satusatunya (Santoso 2011). 
Dalam meningkatkan spiritualitas anak di era digital melalui pembelajaran pendidikan agama Kristen orangtua harus mendidik anak sesuai dengan ajaran dan nasihat Tuhan sebagaimana dikatakan dalam kitab Efesus 6:4 Tuhan menyatakan tanggung jawab setiap ayah untuk mendidik anaknya dalam nasihat dan ajaran Tuhan dengan tidak menimbulkan kemarahan dalam hati anak. Kata "mendidik" yang dipakai dalam ayat ini, dalam bahasa Yunani adalah paideia, mengandung arti mendidik yang menekankan karakter dan prinsip atau nilai hidup (Santoso 2011). Artinya jika orangtua mendidik anak dengan bijaksana, tidak menimbulkan kemarahan dalam hati anak, maka akan menumbuhkan karakter yang indah dalam diri mereka. Hal yang paling penting harus dilakukan oleh setiap ayah, yaitu mendidik anak-anaknya demkian, sebagai misi utama seorang ayah, yakni membawa hati anak ke dalam hati Sang Juruselamat, menuntun anak mengenal Penebusnya (Santoso 2011).

\section{PEMBELAJARAN PAK DALAM PENINGKATAN MORALITAS ANAK DI ERA DIGITAL}

Pembelajaran pendikan agama Kristen di era digital dalam peningkatan moralitas anak merupak tanggung jawab orangtua dalam keluarga.Moralitas merupakan kemauan untuk menerima dan melakukan peraturan, nilai-nilai atau pinsip-prinsip moral. Nilai-nilai moral itu, seperti seruan untuk berbuat baik kepada orang lain, memelihara ketertiban dan keamanan, memelihara kebersihan dan memelihara hak orang lain dan larangan mencuri, berzinah, membunuh, meminum minuman keras dan berjudi. Seseorang dapat dikatakan bermoral, apabila tingkah laku orang tersebut sesuai dengan nilai-nilai moral yang dijunjung tinggi oleh kelompok sosialnya (Eliman 2017:143-44). Dalam hal ini, sangat penting untuk meningkatkan moralitas anak dengan menanamkan nilai-nilai kekristenan dan tata cara kehidupan yang baik sehingga perilaku anak tersebut dapat menghasilkan perilaku yang baik juga dalam kehidupan sehari-hari.

Dalam hal ini, untuk meningkatkan moralitas di era digital sehingga moral anak tersebut dapat menghasilkan perilaku yang baik langkah pertama dalam moralitas Kristen adalah menyerahkan diri kepada Tuhan. Penyerahan ini berarti bahwa kita menjadi seperti Allah (Matius 5:44-48; Lukas 6:35-36). Makin akrab persekutuan kita dengan Allah makin kita mencerminkan sifat-sifat Allah. Oleh karena itu, supaya anak mempunyai perilaku moral yang baik, orangtua sebagai pembimbing harus membawa 
anak untuk menyerahkan kehidupannya kedalam tangan Tuhan dan mengajarkan serta menanamkan kepada anak untuk selalu membangun persekutuan dengan Tuhan, dengan hal itu anak dapat berperilaku yang baik karena anak diajar untuk menaati Firman Allah dan dididik kepribadiannya untuk bertumbuh secara rohani serta anak sudah memahami gaya kehidupan Yesus dengan itu anak dapat merefleksikan dalam kehidupannya sebagaimana dikehendaki Allah yaitu: kehidupan yang memiliki kasih sejati, kehidupan yang berbuah dan adanya kemurnian hidup serta kejujuran (Eliman 2017).

Dengan demikian, pembelajaran pendidikan agama Kristen dalam keluarga untuk meningkatkan moralitas anak di era digital, orangtua perlu menerapkan beberapa hal yaitu: (a) Orangtua harus konsisten dalam mendidik anak, orangtua harus memiliki sikap dan perlakuan yang sama dalam melarang atau membolehkan tingkah laku tertentu kepada anak. Suatu tingkah laku anak yang dilarang oleh orangtua pada suatu waktu, harus juga dilarang apabila dilakukan kembali pada waktu lain. (b) Sikap orangtua dalam keluarga, secara tidak langsung sikap orangtua terhadap anak, sikap ayah terhadap ibu, atau sebaliknya dapat mempengaruhi perkembangan moral anak, yaitu melalui proses peniruan. (c) Penghayatan dan pengalaman agama yang dianut, orangtua merupakan panutan bagi anak, termasuk di sini panutan dalam menjalankan ajaran agama. Orangtua yang membimbing tentang nilai-nilai agama kepada anak, maka anak akan mengalami perkembangan moral yang baik. (d) Sikap konsisten orangtua dalam menerapkan norma, orangtua yang tidak menghendaki anaknya berbohong atau berlaku tidak jujur maka mereka harus menjauhkan dirinya dari perilaku berbohong atau tidak jujur. (e) Orang tua harus membangun komunikasi yang baik dengan anak, sehingga orangtua dapat dengan mudah menanamkan nilai-nilai moral yang baik kepada anak-anak. Orangtua harus bersedia diam tanpa interupsi memancing aliran komunikasi anak. (f) Bimbingan yang berorientasi kasih sayang, diusahakan agar antara orangtua dengan anak terjalin hubungan yang baik, sehingga hubungan kasih sayang akan mendekatkan anak pada orangtuanya serta memudahkan orangtua memberikan nilai-nilai moral (Eliman 2017).

\section{KESIMPULAN}

Sesuai dengan pembasan tentang pembelajaran pendidikan agama Kristen dalam keluarga di era digital untuk meningkatan spiritualitas dan moralitas anak maka dapat disimpulkan bahwa pembelajaran pendidikan 
agama Kristen dalam keluarga sangat penting untuk meningkat spiritualitas dan moralitas anak. Dalam hal ini, untuk meningkatkan spiritualitas anak sesuai dengan nilai-nilai Kristen maka orang harus mengajarkan anak untuk mengasihi Tuhan dengan segenap hati dan jiwa, hidup sesuai dengan kebenaran Firman Tuhan dan mendidik anak sesuai dengan ajaran Tuhan. Orangtua juga bertanggung untuk meningkatkan moralitas anak di era digital melalui pembelajaran pendidikan agama Kristen dalam keluarga. Dalam meningkatkan moralitas anak di era digital orangtua harus konsisten dalam mendidik anak,sikap orangtua dalam keluarga, penghayatan dan pengalaman agama yang dianut, sikap konsisten orang tua dalam menerapkan norma, orangtua harus membangun komunikasi yang baik dengan anak, bimbingan yang berorientasi kasih sayang.

\section{DAFTAR PUSTAKA}

Bertens, K. 2011. ETIKA. Jakarta: PT. Gramedia Pustaka Utama, Cet ke11 .

Boiliu, Noh Ibrahim. 2016. "Misi Pendidikan Agama Kristen Dan Problem Moralitas Anak." Regulafidei Jurnal Pendidikan Agama Kristen Vol 1(No 1):115.

Budiningsih, Asri. 2004. Pembelajaran Moral Berpijak Pada Karakteristik Siswa Dan Budayanya. Jakarta: Rineka Cipta.

Candra, Puspita Adiyani. 2013. "Penggunaan Internet Pada Anak-Anak Sekolah Usia 6-12 Tahun Di Surabaya." Journal Health and Medicine 2(1):1-10.

Carolina L. Radjah, Irene Maya Simon. 2020. "Perkembangan Spiritual Anak Usia SD Dalam Masa Pandemi Covid-19.” Pp. 2-3 in Prosiding Seminar Nasional Universitas Malang.

Djamarah, Syaiful Bahri. 2013. Pola Asub Orang Tua Dan Komunikasi Dalam Keluarga. Jakarta: Rineka Cipta.

Eliman. 2017. "Model Bimbingan Dalam Pendidikan Agama Kristen Terhadap Pembentukan Moral Anak Didik Usia 6-8 Tahun." EPIGRAPHE 1(2):143-44.

Fatmawati, Nur Ika. 2019. "Literasi Digital, Mendidik Anak Di Era Digital Bagi Orang Tua Milenial." Jurnal Politik Dan Sosial Kemasyarakatan 11(2):119-38. 
GP, Harianto. 2017. Teologi Pendidikan Agama Kristen. Yogyakarta: ANDI.

Gulo, Sadiria. 2017. "Prinsip Pendidikan Agama Kristen Dalam Keluaga Bagi Keluarga Banua Niha Keriso Protestan (BNKP) Gunungsitoli." 1(3):456.

Hadi, Sutrisno. 2011. Metode Penelitian, 2nd Ed. Yogyakarta: Andi Offset.

Harianto GP. 2012. Pendidikan Agama Kristen Dalam Alkitab \& Dunia Pendidikan Masa Kini. Yoyakarta: ANDY.

Hastuti, Ruwi. 2013. "Pendidikan Agama Kristen Dalam Keluarga Sebagai Pusat Bermisi." Antusias Jurnal Teologi Dan Pelayanan 4(2):1-15.

Homrighausen. 2012. Pendidikan Agama Kristen. Jakarta: BPK-Gunung Mulia.

Indonesia., Asosiasi Penyelenggara Jasa Internet. 2020. "No Title.” Buletin APJII. Edisi

05-November

2016dalambttps://Media.Neliti.Com/Media/Publications/276725-

Penanaman-Nilai-Nilai-Agama-Dalam-Pendid-734379ad. Pdf. Pada 15/10/2020 16-10.

Kristianto, Paulus Lilik. 2006. Prinsip \& Praktik Pendidikan Agama Kristen No Title. Yogyakarta: ANDY.

Lase, Sudirman. 2011. Pendidikan Agama Kristen Kepada Orang Dewasa. Medan: Mitra.

Lebar, Lois E. 2006. Education That Is Christian: Proses Belajar Mengajar Kristiani Dan Kurikulum. Malang: Gandum Mas.

Maulidiyah, Eka Cahya. 2018. "Penanaman Nilai-Nilai Agama Dalam Pendidikan Anak Di Era Digital." Martabat: Jurnal Perempuan Dan Anak 2(1):73.

Nainggolan, John M. 2009. Pendidikan Agama Kristen Dalam Masyarakat Majemuk. Bandung: Bina Media Informasi.

Nuryanto, Sidik. 2017. "Stimulasi Kecerdasan Spiritual Pada Anak Usia Dini Melalui Kisah." Jurnal Indria: Jurnal Imiah Pendidikan PraSekolah Dan Sekolah Awal 2(1):41-43.

Pribadi, Tati. 2010. Penerapan Moral Bagi Anak Usia Dini. Bandung: Media Informasi. 
Rahmatullah, Azam Syukur. 2017. "Pendidikan Keluarga Seimbang Yang Melekat Sebagai Basis Yang Mencerahkan Anak Di Era Digital." Cendekia 15(2):213.

Rifai, Eliezer. 2012. "Pendidikan Kristen Dalam Membangun Karakter Remaja Di Sekolah Menengah,"." Antusias Jurnal Teologi Dan Pelayanan 2(2):1-17.

Rumahorbo, Benget. 2019. "Peranan Pendidikan Agama Kristen Dalam Pembentukan Spiritualitas Mahasiswa Di Era Revolusi Industri 4.0.” Majalab Ilmiah Methoda 9(3):132-44.

Santoso, M. P. 2011. "Pola Alkitabiah Pendidikan Anak 7-12 Tahun Yang Efektif Untuk Proses Pembentukan Karakter Pemimpin Hamba Di Seminari Anak "Pelangi Kristus." Veritas 1(1):3960.

Santoso, Magdalena Pranata. 2014. “Reaching Family's Sinergity With Christian Church And School To Educate Kid Having Christ's Character." Scientific Repository Petra Christian University Surabaya 04:123.

Setiawan, Wawan. 2017. "Era Digital Dan Tantangannya." Seminar Nasional Pendidikan 2017 1-9.

Sidjabat, Samuel. 1994. Strategi Pendidikan Kristen. Yogyakarta: ANDY.

Sukmanjaya, Bambang. 2017. "Internet Aman, Behavior Based Consultant." 7-9.

Tanudjaja, Rahmiati. 2018. Spiritualitas Kristen Dan Apologetika Kristen. Malang: Literatue Saat.

Thompson, Marjorie L. 2011. Keluarga Pusat Pembentukan Rohani. Jakarta: BPK-Gunung Mulia.

Tong, Stephen. 2001. Arsitek Jiwa 1. Jakarta: BPK-Gunung Mulia.

Turansky, Scottdan Joanne Miller. 2014. Menjadi Orang Tua Kristen. Jakarta Barat: Nafiri Gabriel. 